\title{
Biological characteristics of parasitic Nepinnotheres novaezelandiae within a Perna canaliculus farm
}

\author{
Oliver Trottier*, Andrew G. Jeffs \\ Leigh Marine Laboratory, University of Auckland, Warkworth 0941, New Zealand
}

\begin{abstract}
Pea crabs are commercially significant parasites in the aquaculture production of bivalves in many parts of the world. However, there is scant information available on the biology of these important parasites in aquaculture. The population structure, sex ratio, and breeding status were determined for the pea crab Nepinnotheres novaezelandiae residing in a typical greenlipped mussel Perna canaliculus farm in New Zealand. Of the 324 crabs randomly sampled, there were significantly more female $(82.4 \%)$ than male $(17.6 \%)$ crabs found. The vast majority of crabs $(87.0 \%)$ were sexually mature and of these, females comprised $86.4 \%$ and males $13.6 \%$. However, the sex ratio of immature crabs was relatively even, suggesting that male crabs may have higher mortality while searching for mates. Crab size was highly variable, indicating that recruitment to mussels in the farm was continuous. Carapace width ranged from 4.00 to $11.5 \mathrm{~mm}$, with males tending to be smaller with a mean $( \pm \mathrm{SE})$ carapace width of $6.31 \pm 0.16 \mathrm{~mm}$ versus females with a carapace width of $8.03 \pm 0.06 \mathrm{~mm}$. The crabs did not show any preference for parasitizing mussels of different sexes. Despite the fact that the mussels were only 10 mo old, most female crabs were sexually mature (Stage V) and $89.3 \%$ were gravid. The mean $( \pm$ SE) clutch size was $2592 \pm 579$ and clutch size was directly associated with female carapace width. The mussel farm pea crab population was estimated at $126390 \pm 14144$ individuals, including 93000 gravid females carrying a total of over 241 million eggs. Overall, the results show that pea crabs rapidly colonize farmed mussels and mature quickly to establish a significant breeding population within the mussel farm, with larval output capable of infecting nearby mussel farms as well as wild populations of bivalves.
\end{abstract}

KEY WORDS: Pea crab · Green-lipped mussel $\cdot$ Greenshell ${ }^{\mathrm{TM}} \cdot$ Parasite $\cdot$ Mussel farm $\cdot$ Brachyura Resale or republication not permitted without written consent of the publisher

\section{INTRODUCTION}

The New Zealand pea crab Nepinnotheres novaezelandiae is found throughout New Zealand's coastal waters. Its main host is the green-lipped mussel Perna canaliculus, but it is also found occasionally in a range of other shallow water bivalve species (Palmer 1995). The relationship between pinnotherids and their hosts is often symbiotic, but research has determined the association between $N$. novaezelandiae and its host is an example of biotrophic symbiotic parasitism (Bierbaum \& Ferson 1986, Lackowicz 2005, Trottier et al. 2012). Presence of the parasite within a green-lipped mussel results in a $30 \%$ reduction in mussel shell height and wet mass, likely as a result of the parasite taking food particles filtered out by the host, and causing erosion of the host gills (Wear \& Fielder 1985, Trottier et al. 2012). Gill damage from pea crabs has been shown to significantly lower the rate of oxygen consumption as well as decrease filtration rates of hosts (Bierbaum \& Shumway 1988). A study in New Zealand estimated 
that pea crab infection was responsible for a loss in production across the nation's mussel aquaculture industry of US \$2.16 million annually (Trottier et al. 2012).

Infection levels in wild mussel populations by Nepinnotheres novaezelandiae vary widely and have been reported to range from 4 to $70 \%$ (Jones 1977a, Hickman 1978, Baxter 1981, Bierbaum \& Ferson 1986). Within green-lipped mussel aquaculture an infection level of $5.3 \%$ has been reported, although higher levels are suggested to occur (Trottier et al. 2012).

The life history of Nepinnotheres novaezelandiae has been partially described, with most larval stages inferred from related species (Bennett 1964, Jones 1977b, Wear \& Fielder 1985). After hatching from eggs, the larval development begins with an unknown number of zoeal stages which are presumably followed by a megalopal stage that has never been observed (Wear \& Fielder 1985). The first crab instar is thought to be the invasive stage and is followed by a series of soft carapace stages for both sexes (Jones 1977b, Wear \& Fielder 1985). Males mature from pre-hard to a dorsoventrally flattened hard shell stage and range from 3.2 to $11.8 \mathrm{~mm}$ in carapace width. Females moult through 4 additional stages of soft membranous shells before reaching Stage $\mathrm{V}$, which has a hardened shell and is sexually mature (Jones 1977b, Wear \& Fielder 1985). Stage I (hard stage) females are similar to hard stage males and moult into the soft-shelled Stage II form. Stage II has carapace front that does not project as far forward as in Stage I. The carapace is thin, smooth, colourless and yielding to the touch. Stage III females have abdomen edges that extend beyond the edge of the sternal groove with the third and fourth pleopods being bent above the first further developed segment. Stage IV is very similar to Stage $\mathrm{V}$ except that the abdomen just reaches the coxae of the legs and extends forward to the posterior edge of mouth (Jones 1977b). Stage V females are rounded and range from 9.3 to $20.2 \mathrm{~mm}$ carapace width and their abdomen is as large or larger than the carapace (McLay 1988). Gravid females can be found throughout the year, but a distinctive spike in the numbers of what are believed to be $N$. novaezelandiae zoea has been observed in the water column from August to March (Jones 1977a). Previous studies have shown a low incidence of juvenile pea crab stages recovered from sampled mussels, suggesting that development to adult is very rapid following the invasion of the host bivalve by the juvenile crab (Jones 1977b).
Once settled within the bivalve host, female pea crabs remain within their hosts indefinitely and males leave only for mating (McLay 1988). This hypothesis is supported by the low incidence of multiple pea crabs within one host and the only occasional finding of a male and female pair (Jones 1977b). Crushed male crabs have commonly been recovered after presumably attempting to enter or leave mussels (Jones 1977a). The dorsoventrally flattened profile of male crabs is thought to facilitate their movement in and out of hosts for mating with female crabs. Mate location by male pinnotherids has been proposed to be mediated by pheromone attraction (Asama \& Yamaoka 2009). A chemotactic mating strategy would ensure successful locating of females and reduce the number of times that male crabs would be required to enter or exit a host. Chemoreception is used by mature Nepinnotheres novaezelandiae for locating bivalve hosts, which highlights the chemical sensing ability of this crab (Stevens 1990).

Overall, there is insufficient knowledge about the biology of this parasite which causes financially important damage to commercial mussel aquaculture. Therefore, the aim of the current study was to examine the population structure, sex ratio, and breeding status of this pea crab within a typical green-lipped mussel farm in New Zealand.

\section{MATERIALS AND METHODS}

\section{Sampling}

Mussels were acquired and processed as part of a large-scale systematic sampling of a 1.71 ha greenlipped mussel farm in December 2010. The farm was located in northern New Zealand at Great Barrier Island and used a modified Japanese long-line shellfish aquaculture method, which is the most commonly used method for the culture of green-lipped mussels in New Zealand (Jeffs et al. 1999). The farm covered an area of approximately $90 \times 160 \mathrm{~m}$ with 9 pairs of parallel backbone lines spaced at $10 \mathrm{~m}$ intervals on the surface of the water. Dropper lines suspended from the backbone lines held a crop of $\sim 10$ mo old mussels. The paired backbone lines consisted of $35 \mathrm{~mm}$ polypropylene rope that was anchored at both ends and supported by plastic floats. The dropper lines, with attached green-lipped mussels, were composed of $20 \mathrm{~mm}$ polypropylene rope and suspended in a U shape between backbone pairs at $1 \mathrm{~m}$ intervals to a depth of about $10 \mathrm{~m}$. Sea 
floor depth at low tide was $10 \mathrm{~m}$ on the western side of the farm and gradually increased to $15 \mathrm{~m}$ on the eastern side.

Sampling was carried out by a random stratified method on the backbones. Weighted sampling lines were placed at 15 locations, about $10.5 \mathrm{~m}$ apart, on each of backbones 1, 3, 5, 7 and 9 (Trottier et al. 2012). Dropper lines were stratified into 3 sampling regions: top (0 to $4 \mathrm{~m}$ depth), middle (4 to $8 \mathrm{~m}$ depth), and bottom (8 to $12 \mathrm{~m}$ depth). Sample lines were $12 \mathrm{~m}$ in length and composed of $3 \mathrm{~mm}$ polypropylene rope with 3 nylon sample bags placed at the centre of each sampling depth. For each sampling depth, 30 mussels were randomly sampled and placed in their respective bag by SCUBA divers. Mussel density counts of droppers were taken at 2,6 and $10 \mathrm{~m}$ depths at each end and the centre of all backbones in triplicate. A total of 6750 mussels were sampled and processed, producing a total of 324 crabs.

\section{Sample processing}

The 30 mussels from each bag were shucked to determine pea crab infection level and acquire pea crab samples. All infected and 10 randomly chosen uninfected mussels were processed from each bag. Biometric measurements included mussel shell height and crab carapace width, which were measured with a digital calliper to an accuracy of $0.01 \mathrm{~mm}$. After being measured, crabs were preserved in $10 \%$ formalin sea water. Eggs were separated from gravid females prior to preservation. Observations of crab sex and egg stages were made under a dissecting microscope at a $60 \times$ magnification with crab and egg stages keyed according to Jones (1977b). Male crabs were determined to be mature when they were hard stage with a well-calcified creamy white carapace containing distinctive orange markings and long gonopods. Mature females were denoted by a smooth, membranous and oval carapace that was opaque white and an abdomen that was as large, or larger than the carapace. Egg development was divided into 3 stages based on the colour of the eggs: red, newly extruded eggs (Stage 1) which matured into orange eggs (Stage 2), and finally brown-yellow eggs, which were eyed ova (Stage 3) (Jones 1977b).

\section{Crab sex ratio and reproductive characteristics}

Female crab fecundity was measured by combining the means of triplicate egg counts of clutches.
Clutches of eggs from individual female crabs were poured onto a gridded slide for counting. Counts were performed under a dissecting microscope at $15 \times$ magnification with a hand tally counter.

Host mussel sex was determined by histological analyses. Sections of gonads were excised as mussels were processed and immediately fixed in Bouin's solution. Fixed samples were then placed in a vacuum infiltration processor (VIP) before being embedded in paraffin and sectioned at $7 \mu \mathrm{m}$. Gonad sections were stained with haematoxylin and eosin and mounted with Eukit ${ }^{\circledR}$. Samples were then sexed according to Buchanan (1998) and Alfaro et al. (2001) using a compound microscope at $400 \times$ magnification.

\section{Characteristics of mussel farm crab population}

Total fecundity of the crab population on the mussel farm was derived by first estimating the farm's Nepinnotheres novaezelandiae population. This was done by combining the mussel population estimate $( \pm \mathrm{SE})$ of $2384730( \pm 73840)$ with the overall infection level of $5.3 \pm 0.062 \%$ as reported previously using spatial abundance modelling (Trottier et al. 2012). The proportion of gravid females within the crab population was calculated by dividing the observed number of gravid females by the total mature (Stage V) female count. The total farm fecundity was then calculated by combining the $N$. novaezelandiae population estimate with the gravid female proportion and the mean female crab fecundity within the mussel farm.

\section{Statistical analyses}

The sex ratio of the population for mature and immature pea crabs found within the mussel farm were compared with a chi-square goodness of fit test, with an expected male:female ratio of 1:1. The relationship of the presence of pea crabs with male versus female mussels was also tested with a chi-square goodness of fit test. Pearson correlation analyses were used to examine the relationship between female egg count and crab size as well as between crab carapace width and the shell height of the mussel host. Student's $t$-test was used to compare the mean values of male and female crab carapace width and the shell height of infected and uninfected mussels. A chi-square test of independence was used to determine whether the abundance of pea crabs of each sex was independent of the position of the backbone line within the farm. 


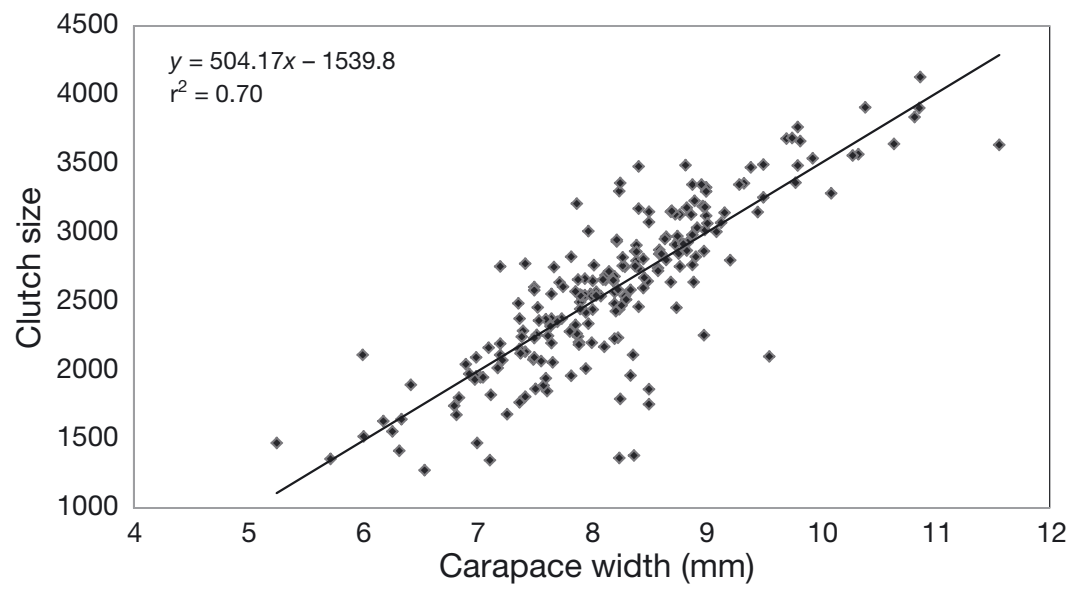

Fig. 1. Nepinnotheres novaezelandiae. Clutch size versus carapace width of female pea crabs. Each $\mathrm{mm}$ increase in female carapace corresponds to an increase in female carrying capacity of $\sim 500$ eggs

spectively. Stage 3 eggs accounted for the majority $(54.1 \%)$ of total clutches observed.

\section{Crab size frequency}

The carapace width of all sampled crabs ranged from 4.00 to $11.5 \mathrm{~mm}$ (Fig. 2) and mean ( $\pm \mathrm{SE})$ carapace width of the whole population was $7.74 \pm 0.07 \mathrm{~mm}$. However, the mean carapace widths of male and female crabs were significantly different, i.e. $6.31 \pm 0.16$ and $8.03 \pm 0.06 \mathrm{~mm}$, respectively (Student's $t$-test, $\mathrm{p}=$ 0.00). Crab size frequency had a normal distribution with males absent

\section{RESULTS}

\section{Crab sex ratio and reproductive characteristics}

Of the 324 crabs retrieved from the 6750 sampled mussels, significantly more were female $(267,82.4 \%$ ) than male $(57,17.6 \%)\left(\chi^{2}=132\right.$, df $=1, \mathrm{n}=324, \mathrm{p}=$ 0.00). Only a single instance of a male and female pair within a single mussel was observed. Of all the crabs that were sampled, $87.0 \%$ were mature. Of all mature crabs, the female and male proportion was 86.4 and $13.6 \%$ respectively. Sex distribution of immature crabs was statistically equal with females comprising $54.7 \%$ and males $45.3 \%\left(\chi^{2}=0.381, \mathrm{df}=1, \mathrm{n}=\right.$ $42, \mathrm{p}=0.53$ ). Immature male and female crabs ranged in size from 4.10 to $8.00 \mathrm{~mm}$ and 4.10 to $8.20 \mathrm{~mm}$, respectively. Mature male and female crabs ranged in size from 4.30 to 9.30 and 4.90 to $11.5 \mathrm{~mm}$, respectively. The mean $( \pm \mathrm{SE})$ egg count from the 217 female clutches sampled was $2590 \pm$ 579 and clutch size ranged from 1272 to 4128 . The clutch size of female pea crabs was found to be directly related with maternal crab size as measured by carapace width (Pearson correlation analysis, $\mathrm{r}^{2}=0.83, y=504.17 x-$ 1539.8), with every additional millimetre of carapace width of a female crab corresponding to an average increase in clutch size of 500 eggs (Fig. 1). Stage 1 and 2 eggs comprised 27.3 and $18.6 \%$ of clutches, re-

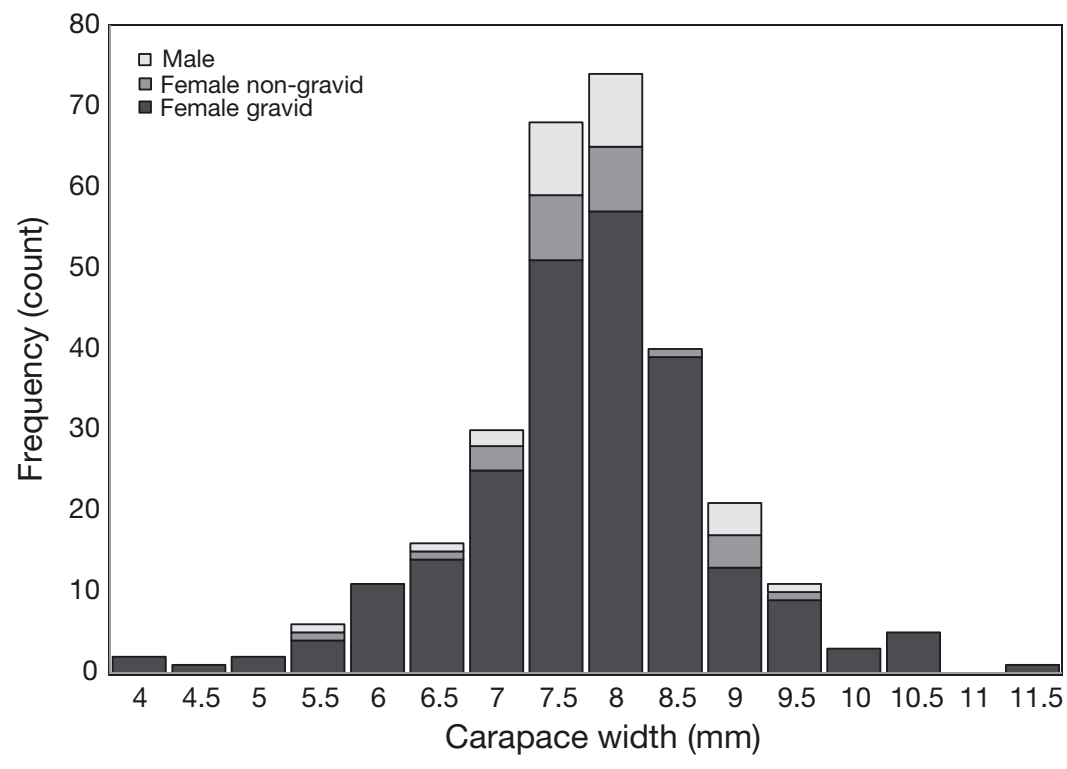

Fig. 2. Nepinnotheres novaezelandiae. Carapace width of 324 pea crabs randomly sampled from a green-lipped mussel farm in northern New Zealand. Males accounted for $17.6 \%$ (57) and females for $82.4 \%$ (267) of the total sample 


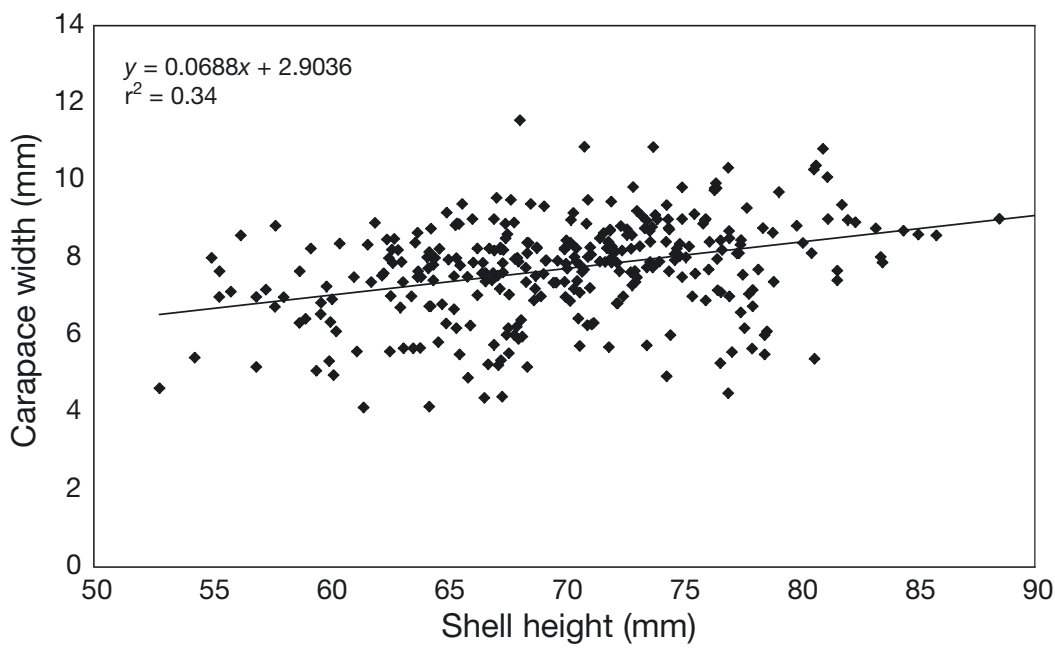

Fig. 3. Nepinnotheres novaezelandiae and Perna canaliculus. Carapace width of pea crabs versus the shell height of their green-lipped mussel host. The association between crab size and host size was statistically significant for the whole sample $(p=0.00)$ and separately for females $\left(r^{2}=0.36, p=0.00\right)$ and males $\left(\mathrm{r}^{2}=0.53, \mathrm{p}=0.00\right)$

$\left(\mathrm{r}^{2}=0.53, \mathrm{p}=0.00\right)$. Host mussel shell height ranged from 45.4 to $96.5 \mathrm{~mm}$. Mean $( \pm \mathrm{SE})$ shell heights of infected and uninfected mussels were $70.1 \pm 0.38$ and $80.8 \pm 0.12 \mathrm{~mm}$, respectively, and significantly different (Student's $t$-test, $\mathrm{p}=0.00$ ). Mean shell heights of males and females were $68.6 \pm 0.95$ and $70.4 \pm$ $0.41 \mathrm{~mm}$, respectively, and not statistically different (Student's $t$-test, $\mathrm{p}=0.07$ ).

Pea crabs showed no preference for host mussels of either sex. Female accounted for $43 \%$ and males $57 \%$ of infected mussels; this was not statistically different from an even ratio $\left(\chi^{2}=1, \mathrm{df}=1, \mathrm{n}=49, \mathrm{p}=\right.$ 0.32 ), as is to be expected in this population of dioecious bivalves (Alfaro et al. 2001).

\section{Sex proportion among backbones}

A chi-square test of independence was performed to examine the relationship between pea crab abundance of both sexes and backbone placement within the farm. The relation between these variables was not significant $\left(\chi^{2}=0.496, \mathrm{df}=4, \mathrm{n}=324, \mathrm{p}=0.97\right)$.

\section{Characteristics of mussel farm crab population}

The total number of infected mussels over the entire 1.71 ha mussel farm, and therefore the crab population living on the farm at the time of sampling was estimated to be $126390 \pm 14144$ individuals.
When the observed sex ratio from our sampling is applied to this estimate, approximately 104145 crabs are female and 22244 are male. Within the total crab population, Stage V females capable of reproduction accounted for an estimated 95188 individuals and 93001 of them were estimated to be gravid. The total standing egg count on the mussel farm at the time of sampling was estimated to be approximately 241 million eggs.

\section{DISCUSSION}

A mussel farm represents a unique set of circumstances for a bivalve parasite, such as the pea crab Nepinnotheres novaezelandiae. The spatial structure of a mussel farm is significantly different from benthic and intertidal communities, and environmental conditions such as direct wave action and substrate contact are absent. Intertidal height among wild populations is thought to frequently determine the abundance of pea crabs in mussels, since longer submergence time increases access to the host and opportunities for infection by the parasitic crabs (Houghton 1963, Beach 1969, Seed 1969, Kruczynski 1974). The host population in a mussel farm has distinctive characteristics, in that the mussels are all of equal age, densely aggregated, fast-growing, permanently submerged and therefore readily accessible.

Overall, there were nearly 5 times more female than male crabs found in the mussel farm. A similar skewed sex ratio, with up to $81.6 \%$ females, has also been observed in wild populations of green-lipped mussels in New Zealand (Jones 1977a). A dominant female sex ratio has also been observed in related parasitic crab species such as Arcotheres tivelae (91\%) (Saeedi \& Ardalan 2010), Pinnotheres maculatus (72\%) (Kruczynski 1974), and P. sinensis (Sun et al. 2006). In the present study, the sex bias was uniform and not influenced by the location of the crabs on the farm, as there was no relationship between the relative abundance of the sexes and the location of the backbone lines. However, the sex ratio of immature crabs was not different from 1:1, suggesting that differential male mortality occurs after reaching maturity. Previous studies have commonly found crushed male crabs after they have apparently attempted to enter or leave mussels, probably for the 
purpose of mating with females (Jones 1977a). A 1:1 birth sex ratio among crustaceans is suggested to be advantageous to the species despite post-maturity mortality (Leigh 1970).

In this current study, there was only a single instance of a male and a female crab being found in the same host out of the 6750 mussels examined and 324 crabs found, whereas a previous report with a smaller sample size of 486 wild mussels found a greater proportion (8 pairs) of co-habiting couples out of a total of 198 crabs found (Jones 1977a). It is possible that males are able to move among mussels for the purpose of finding mates more easily in an aquaculture mussel population than in a wild population, where mussels may be less accessible.

In this study a total of 218 gravid females were found and, since female crabs are unable to leave their host, males must have visited the female at some point to mate (Jones 1977a, Hickman 1978, Baxter 1981, Lackowicz 2005). Sperm storage has been noted in some species of pea crabs but the mating behavior in Nepinnotheres novaezelandiae has never been observed. However, pinnotherids do contain ventral seminal receptacles which would allow for hard-stage mating and sperm storage (Becker et al. 2011, McLay \& López Greco 2011). Male N. novaezelandiae are thought to leave their host mussel in search of females, similar to the behavior observed in Pinnotheres pisum and P. ostreum (Jones 1977a). This behavior is unusual, as most species of pinnotherids, such as P. maculatus and Fabia subquadrata, form free-swimming copulatory swarms of crabs (Pearce 1966). The low proportion of adult male crabs observed in this study (13.6\%) is likely due to predation at times when the male crabs leave the protection of their hosts to find mates. Male $N$. novaezelandiae have been observed crushed by the shell rim of their mussel hosts (Jones 1977a). A study on the pea crab $P$. ostreum found that males were killed $13 \%$ of the time that they attempted to enter a bivalve host (Stauber 1945). Although our results indicated a 1:1 sex ratio for juvenile crabs, differential rates of mortality for mature male crabs resulting from mate searching could explain the heavily female-biased female:male adult sex ratio ( 9:1) observed in this study.

The mussels within the farm at the time of sampling were 10 mo old since seeding-out on the dropper lines as early juvenile mussels. Thus, $89.3 \%$ of the sampled female crab had settled and grown to reach maturity inside this time frame. The association between crab size and host size was statistically significant for both females $(p=0.00)$ and males $(p=$
0.00) (Fig. 3). The carapace size of sampled individuals ranged from 4.00 to $11.5 \mathrm{~mm}$, and the vast majority of crabs collected from these mussels were mature adults $(87.0 \%)$ (Fig. 2). This suggests that the maturation rate of Nepinnotheres novaezelandiae from juvenile stages within a mussel farm is relatively rapid. Free-swimming Pinnotheres taichungae (previously reported as $P$. bidentatus) grow at $1 \mathrm{~mm} \mathrm{mo}^{-1}$ carapace width, and $N$. novaezelandiae, with the protection of a host offering a potentially unlimited food supply, would have greater potential for rapid development (Hsueh 2001). Fast growth and short moulting stages would also advance the number of mature males entering the adult population and alleviate mating restrictions imposed by the apparently high rate of adult male mortality. The limiting factor for reproduction of these mature females is likely to be acquisition of sperm from males, a situation aggravated by their scarcity. It is likely that female crabs within this population reproduce several times annually. The farm-wide fecundity of 241 million eggs estimated in this study provides an instantaneous measurement and is likely to therefore be an underestimate of the annual reproductive capability of the crab population within the farm. Reproductive output may also increase in parts of New Zealand where mussel crop growth is much slower. This slower growth rate would delay harvest time for the mussels and potentially give the crabs more time to settle and grow. Our results indicate an increased clutch size of about 500 eggs for every millimeter of growth in the female carapace width (Fig. 1). Greenlipped mussel farms within New Zealand are usually harvested after 10 to 18 mo at which time the pea crab population is probably increasing via ongoing infection with settlers. The high reproductive output of pea crabs has the potential to increase the recruitment of these parasites into local wild and farmed populations of mussels and other bivalves (Trottier et al. 2012).

Brown-yellow (eyed ova) eggs comprised the majority of the 3 egg stages observed. Red and orange stages were less frequent, suggesting that these earlier egg stages are shorter in duration and that eggs mature quickly once extruded. The brood period of Nepinnotheres novaezelandiae eggs is unknown, although in other crab species it can be as short as $8 \mathrm{~d}$ from egg until hatching to the first zoea (Arshad et al. 2006). Rapid maturation of eggs and therefore a short clutch retention period could allow pea crabs a higher number of repeat spawnings in a year. This would aid the parasite in infecting new hosts in farms and wild populations and 
also allow for rapid establishment and recolonization of new hosts.

Mussel spat used to seed the farm sampled in this study is sourced from the northern end of the country at Ninety Mile Beach (Jeffs et al. 2000, Alfaro et al. 2010). This source of spat is used to supply the majority of New Zealand green-lipped mussel aquaculture operations. Previous research on the spat collected from this location indicated an equal sex distribution of males and females among the spat (Alfaro et al. 2010). Histological analyses of host gonads demonstrate the absence of a preference for either sex of host. The selection of male (57\%) and female (43\%) mussel hosts by the crab parasites was statistically equal $\left(\chi^{2}=1, \mathrm{df}=1, \mathrm{n}=49, \mathrm{p}=0.32\right)$. These results suggest that pea crabs' choice of host is not based on sex but on other factors such as sea floor depth and host access (Trottier et al. 2012). Submerged greenlipped mussel from farms therefore would provide an ideal habitat that was always accessible and devoid of the heavy wave action that affects intertidal mussel populations.

Further research is needed into pea crabs, as methods for reducing infection levels need to be specifically tailored to the biology of this parasite in order to maximize efficiency. Interfering with larval settlement could potentially be achieved by using chemical or acoustic traps. The chemoreceptive ability of Nepinnotheres novaezelandiae with respect to host preference has been well documented (Stevens 1990). Settlement could also be influenced by a number of sensory cues, as has been found for many other crustaceans, including the presence of adult conspecifics (Welch et al. 1997), host-odour (Stevens 1990) and acoustic cues (Stanley et al. 2009). Trapping adult male pea crabs by taking advantage of the probable use of pheromone mate location also provides an attractive option for restricting successful reproduction.

\section{CONCLUSIONS}

Our results show that pea crabs have the ability to colonize and establish a highly reproductive population on mussel farms very quickly. This is achieved by rapid growth, early maturation, and high female fecundity. Mussel farms quickly become a larval source for the parasites that may cause a significant and localized spill-over effect into neighboring wild and farm populations of bivalve shellfish. The rapid maturation of eggs and juveniles combined with product losses incurred by Nepinnotheres novaeze- landiae highlight the need for further investigation into their larval and reproductive biology in order to further develop parasite management strategies. In particular, research is needed into the mating pheromone systems as it could provide the best target for bio-control that is specifically aimed at males, which would take advantage of the skewed sex ratio and optimize the effect of control measures.

Acknowledgements. This research was supported by the University of Auckland Doctoral Scholarship Fund and the Glenn Family Foundation. We are very grateful to Peter Vitasovich of Greenshell New Zealand for access to the farm and sampled mussels. Many thanks to Pheobe Armatige, Ashleigh Robins, and Mandy Bradshaw for the many hours spent processing mussels and crabs. This work was conducted under University of Auckland Animal Ethics Committee approval number R864.

\section{LITERATURE CITED}

Alfaro AC, Jeffs AG, Hooker SH (2001) Reproductive behaviour of the green-lipped mussel, Perna canaliculus, in northern New Zealand. Bull Mar Sci 69:1095-1108

Alfaro AC, McArdle B, Jeffs AG (2010) Temporal patterns of arrival of beachcast green-lipped mussel (Perna canaliculus) spat harvested for aquaculture in New Zealand and its relationship with hydrodynamic and meteorological conditions. Aquaculture 302:208-218

Arshad A, Efrizal KMS, Kamarudin MS, Saad CR (2006) Study on fecundity, embryology and larval development of blue swimming crab Portunus pelagicus (Linnaeus, 1758) under laboratory conditions. Res J Fish Hydrobiol 1:35-44

Asama H, Yamaoka K (2009) Life history of the pea crab, Pinnotheres sinensis, in terms of infestation in the bivalve mollusc, Septifer virgatus. Mar Biodiver Rec 2: 1-5

Baxter AS (1981) Ecology of the New Zealand pea crab, Pinnotheres novaezelandiae Filhol, 1886 (Brachyura: Pinnotheridae). BSc Honours thesis, University of Canterbury, Christchurch

Beach NW (1969) The oyster crab, Pinnotheres ostreum Say, in the vicinity of Beaufort, North Carolina. Crustaceana 17:187-199

> Becker C, Drandis D, Storch V (2011) Morphology of the female reproductive system of European pea crabs (Crustacea, Decapoda, Brachyura, Pinnotheridae). J Morphol 272:12-26

Bennett EW (1964) The marine fauna of New Zealand: Crustacea Brachyura. Bulletin 153, New Zealand Department of Scientific and Industrial Research, Wellington

Bierbaum RM, Ferson S (1986) Do symbiotic pea crabs decrease growth rate in mussels? Biol Bull 170:51-61

Bierbaum RM, Shumway SE (1988) Filtration and oxygen consumption in mussels, Mytilus edulis, with and without pea crabs, Pinnotheres maculatus. Estuaries Coasts 11:264-271

Buchanan S (1998) Spat production of the greenshell mussel Perna canaliculus in New Zealand. PhD thesis, University of Auckland 
Hickman RW (1978) Incidence of a pea crab and a trematode in cultivated and natural green-lipped mussels. NZ J Mar Freshw Res 12:211-215

Houghton D (1963) The relationship between tidal level and occurrence of Pinnotheres pisum in Mytilus edulis. $\mathrm{J}$ Anim Ecol 32:253-257

> Hsueh PW (2001) Population dynamics of free-swimming stage Pinnotheres bidentatus (Brachyura: Pinnotheridae) in tidal waters of western central Taiwan. J Crustac Biol 21:973-981

Jeffs AG, Holland RC, Hooker SH, Hayden BJ (2000) Overview and bibliography of research on the Greenshell mussel Perna canaliculus from New Zealand waters. J Shellfish Res 18:347-360

> Jones JB (1977a) Natural history of the pea crab in Wellington Harbour, New Zealand. NZ J Mar Freshw Res 11: 667-676

> Jones JB (1977b) Post-planktonic stages of Pinnotheres novaezelandiae Filhol, 1886 (Brachyura: Pinnotheridae). NZ J Mar Freshw Res 11:145-158

Kruczynski WL (1974) Relationship between depth and occurrence of pea crabs, Pinnotheres maculatus, in blue mussels, Mytilus edulis, in the vicinity of Woods Hole, Massachusetts. Chesapeake Sci 15:167-169

Lackowicz LS (2005) Population biology of mussel (Aulacomya maoriana, Mytilus galloprovincialis and Perna canaliculus) from rocky intertidal shores in Wellington Harbour. PhD thesis, Victoria University of Wellington

Leigh EG Jr (1970) Sex ratio and differential mortality between the sexes. Am Nat 104:205-210

McLay CL (1988) Brachyura and crab-like anomura of New Zealand. Leigh Lab Bull 22:1-463

McLay CL, López Greco LS (2011) A hypothesis about the origin of sperm storage in Eubrachyura, the effects of seminal receptacle structure on mating strategies and the evolution of crab diversity: How did a race to be firs become a race to be last? Zool Anz 250:378-406

Palmer P (1995) Occurrence of a New Zealand pea crab,

Editorial responsibility: Robert Poulin,

Dunedin, New Zealand
Pinnotheres novaezelandiae, in five species of surf clam. Mar Freshw Res 46:1071-1075

Pearce JB (1966) The biology of the mussel crab, Fabia subquadrata, from the waters of San Juan Archipelago, Washington. Pac Sci 20:3-35

Saeedi S, Ardalan AA (2010) Incidence and biology of Arcotheses tivelae (Crustacea: Decapoda) in Amiantic umbonella (Bivalvia: Veneridae) on the northern coat of the Persian Gulf, Iran. J Mar Biol Assoc UK 90:655-661

$>$ Seed R (1969) The incidence of the pea crab, Pinnotheres pisum in the two types of Mytilus (Mollusca: Bivalvia) from Padstow, south-west England. J Zool 158:413-420

Stanley JA, Radford CA, Jeffs AG (2009) Induction of settlement in crab megalopae by ambient underwater reef sound. Behav Ecol 21:113-120

Stauber LA (1945) Pinnotheres ostreum, parasitic on the American oyster Ostrea (Gryphaea) virginica. Biol Bull 88:269-291

Stevens PM (1990) Specificity of host recognition of individuals from different host race of symbiotic pea crabs (Decapoda: Pinnotheridae). J Exp Mar Biol Ecol 143: 193-207

Sun W, Sun S, Yuqi Y, Baowen Y, Weibo S (2006) The prevalence of the pea crab, Pinnotheres sinensis, and its impact on the condition of the cultured mussel, Mytilus galloprovincialis, in Jiaonan waters (Shandong Province, China). Aquaculture 253:57-63

Trottier O, Walker D, Jeffs AG (2012) Impact of the parasitic pea crab Pinnotheres novaezelandiae on aquacultured New Zealand green-lipped mussels, Perna canaliculus. Aquaculture 344:23-29

Wear RG, Fielder DR (1985) The marine fauna of New Zealand: larvae of the brachyura (Crustacea, Decapoda). NZ Oceanogr Inst Mem 92:1-90

> Welch JM, Rittschof D, Bullock TM, Forward RB Jr (1997) Effects of chemcial cues on settlement behaviour of blue crab Callinectes sapidus postlarvae. Mar Ecol Prog Ser 154:143-153

Submitted: March 12, 2012; Accepted: July 10, 2012 Proofs received from author(s): September 22, 2012 